\title{
Reflections on the Protection and Inheritance of Local Culture in the Process of Urbanization
}

\author{
Zhou Yongbin ${ }^{1, a}$ \\ ${ }^{1}$ Baicheng Normal College, Media Institute, Baicheng, Jilin \\ a84625006@qq.com
} Keywords: New Urbanization; Local Culture; Protection and Inheritance; Rural Areas; Ecological
Civilization; Local Culture

\begin{abstract}
The new urbanization should have cultural connotation and humanistic spirit, rather than simply seeking spatial expansion and scale expansion. Urbanization process, in particular, should pay attention to the cultural heritage of the city. As a result of utilitarianism, cultural protection awareness is weak, urban construction awareness of a single factor, leading to the existence of urbanization in China to the city, demolition and destruction, thousands of side and other issues. Protect and inherit the local culture is the new urbanization construction of the meaning of the title.
\end{abstract}

\section{Introduction}

Under the impetus of the social economy, the process of urbanization in our country has been accelerating, and the rural economy has also achieved a better development, which brings great convenience to the villagers' life. Local culture is a key component in the construction of rural ecological civilization and a key component of the rural economic system. However, in the actual situation, although the new rural construction has developed greatly, the local cultural protection is not ideal, A variety of hidden dangers. Therefore, the relevant departments must enhance the protection of local culture and heritage awareness, improve the relevant system norms, so as to better promote the steady construction of rural ecological civilization.

\section{The Significance of the Protection and Inheritance of Local Culture in the Construction of New Urbanization}

Local culture, also known as rural culture, rural culture and village culture, as a type of culture, is also a natural definition of trouble. The local culture is an indispensable part of the study of rural sociology. At present, there is no definition of the concept of "local culture". At the same time, there is no unified concept of rural culture, village culture. the village culture made the following definition, it is a kind of regional culture, a kind of farmers as the main body of rural residents culture. It refers to the farmers in the long history of the process, the creation and formation of the sum of spiritual civilization, including the farmers' ideals, feelings, beliefs, values, ethics, customs, lifestyle, behavior norms, etc.. Village culture has the following characteristics: local, patriarchal ethics, closed, conservative, egalitarian and satisfaction and experience of thinking.

Hundreds of years, the social nature Chinese society has changed several times, from the feudal society by the semi feudal and semi colonial society in transition to a socialist society, rural China with historical tide or float or sink. There are many changes in the rural social environment that the local culture depends on. After that, a mention in rural culture cannot do without talking about "local nature". Therefore, rural culture can be called local culture. Since the reform and opening up decades, local cultural changes rapidly, the local culture has become a hot issue in the field of social science, the related literature is books are numerous.

Local culture is mainly derived from people's daily life, in a long period of integration, the formation of a certain characteristic of cultural content, and penetrate into people's daily lives. The local culture contains a variety of content, including rural customs, habits and cultural environment, there are a variety of non physical products and physical products, including people's spiritual and 
emotional expression, has an important role in the progress of the rural culture. In real life, each village has a different cultural traditions, cultural practices, with a certain degree of integration and personality, so in the long run, the local culture has a higher heritage, educational value.

\section{Local Culture Crisis and Disorder}

Study on the local culture in the present, there are a number of scholars put forward "in the city under the impact of local culture, threatened by growing crises serious disorder" judgment. because modern factors penetrate to the full range of rural areas, with a strong characteristic of consumerism of modern media into the countryside, the idea of personal village, village legal concept based on individual rights, which makes the relatively closed village began to disintegrate, traditional culture and local beliefs are serious and difficult to survive extrusion. The countryside and the farmer are more and more marginalized in the society and the culture. In the rapid social changes, farmers can no longer gain a sense of long tradition of life is stable, and can not get the modern meaning of life from advertising and fashion to lead the values of consumerism, farmers were thrown into a modern and tradition has been lost, can not have the embarrassing situation, and thus in general sense, farmers unable to rootlessness and anxiety. whether the modernization of Chinese characteristics should be reflected in the single mode of urbanization? In enumerating the necessary material basis to create a new life in rural areas at the same time, he pointed out that more relative to the low quality of material life, a long history of traditional and local flavor of rural culture is lack of almost all gone, the city commercial society made the pop culture, not cut the reality of rural life style and value has penetrated into every corner of the country, which is reflected in both the conscious pursuit of rural education, is also reflected in the details of life of young farmers. under the impact of modern industrial civilization, the cultural ecology of rural areas in the past more than and 20 years has been greatly damaged, and is in a bad situation. This is not only the local art of the fall, cultural forms have been destroyed, more important is the face of city culture and colonial penetration, the vast rural areas generally appeared a kind of unconscious mental anxiety and cultural anxiety.

\section{Protection and Inheritance of Local Culture in the Construction of New Urbanization}

The protection and inheritance of local culture is the foundation and key process of urbanization construction, if the local culture is gradually lost, not only bring negative influence to the development of the rural economy, but also bring unfavorable to the construction of rural ecological civilization normal therefore, strengthen local culture protection and inheritance is very important. With the continuous deepening of the cultural trend of thought on the local culture, the relationship between the material and spiritual culture has gradually been isolated, people are more inclined to the pursuit of the material world, but ignore the value of spiritual culture. Therefore, the government must clear the importance of the construction of local culture, strengthen the protection and inheritance of local culture, so as to better promote the smooth progress of rural ecological civilization construction.

Relevant departments need to build a variety of cultural infrastructure in accordance with the actual situation of the country, to provide various resources for the construction of rural ecological civilization. In the actual situation, due to the lack of investment in the construction of local culture, resulting in the establishment of various types of cultural infrastructure is relatively backward, the cultural construction of resources and places of defects, to the villagers' cultural life of the normal adverse. Therefore, the government of the local cultural construction situation of reasonable analysis, effective construction of the cultural infrastructure, including cultural centers, cinemas, libraries and other infrastructure, and to encourage the villagers to participate in various cultural activities, including various carnivals, opera performances, and give full play to local characteristics, so that the villagers are willing to participate in and eager to participate in. In various cultural activities under the action to allow the villagers to continuously improve the enthusiasm to participate in various cultural work, and gradually establish a local culture and heritage protection 
consciousness, some valuable cultural forms of publicity, and into all kinds of tourist industry, it can not only promote the development of local culture, but also can bring great convenience for the economic development of rural areas. In this case, the local culture can be better protected and inherited, but also to promote the smooth progress of rural ecological civilization construction.

The government departments should strengthen the cultural education of the villagers, and cultivate the talents of cultural construction. In fact, although the importance of the protection of local culture gradually, but many villagers do not have good local cultural awareness, lack of awareness of protection and inheritance, resulting in the development of local culture is greatly hindered. Therefore, the government must strengthen the cultural education of the villagers. To understand the situation of education in the local culture, the government must increase the educational investment, the enthusiasm of the villagers to receive education, to meet the material and spiritual needs of the villagers, allowing it to self-regulated learning and cultural knowledge, and actively participate in the process of rural culture construction, so as to better promote the protection and inheritance of local culture.

Government departments can vigorously develop the cultural industry in accordance with local conditions. Local culture gradually formed by the elements in people's daily life in the days and months multiplying, it consists of a variety of spiritual products and material products in the local culture, with high cultural value. So the government departments can accurate understanding of the local culture, give full play to the advantages of resources, development of tourism industry and national activities, create the cultural characteristics of the brand, and increase publicity, to attract more tourists, so as to better promote the protection and inheritance of local culture.

To sum up, the protection and inheritance of local culture is the key to promote the construction of ecological civilization in rural areas, which plays an important role in the development of rural economy. However, in reality, many rural areas do not pay attention to the protection of local culture, but blindly economic construction, resulting in the gradual loss of local culture. Therefore, the relevant departments must improve the relevant institutional norms, and strengthen the education of the villagers, to strengthen the protection and inheritance of local culture, so as to better promote the smooth progress of rural ecological civilization construction.

\section{The New Town of Local Cultural Heritage Function}

Towns must inherit local culture. The city is the city of the people, the culture is the intrinsic request of the people, the urban construction finally points to the person, is for the survival of the human survival condition to carry on. Urbanization is not simply to urbanization, but the urbanization of people. The purpose of urbanization is human, and human beings must be the existence of culture. This determines the urbanization is not simply the construction of the problem, but to human core, how to build the problem. Not to put people in the cage of the building, but to allow the existence of human culture, especially from the existing cultural traditions.

Protection of cultural heritage and urbanization integration. The local culture heritage of urbanization is the responsibility, the extension of the protection of cultural heritage development, showing the new features: one is in the protection of cultural heritage protection from the elements, pay attention to the single factor at the same time to pay attention to the cultural heritage, natural elements and elements of interaction and the formation of mixed heritage, cultural landscape protection direction; two is in the type of cultural heritage protection, protection from the emphasis on static heritage, while focusing on the development of "dynamic heritage" and "living heritage protection direction; three is in the nature of cultural heritage protection, attention from the protection of important historic buildings. It can be seen from the new features of the protection of cultural heritage that the original ecological environment of cultural heritage is more and more important. The vast rural areas, is the cultural heritage of the original ecological storage sites and space. Therefore, the protection and inheritance of culture must be integrated with the urbanization, which endows the town with the responsibility to protect the local culture.

Functional city is bound to cultural city. Inheriting local culture is the meaning in the process of urbanization. In 1933, the fourth meeting of the International Association of modern architects 
proposed the "functional city" of the Athens charter. The charter is based on the concept of functional zoning of the city, and pointed out that the city's residential, work, recreation and transportation to coordinate the four functions of the balance of development. The concept of functional city has an important influence on urban planning and development. With the development of economy and society, more and more people recognize that the function of city development is only city development and cultural dimension, and poetic city development should become an important supplement to the functions of the city, and is the core content of the city development. The city is one of the city, only to meet the cultural dimension of human existence is the future direction of development of the city, the city will go to city cultural function, the local culture heritage has become in the process of urbanization in the meaning of.

\section{Suggestions on the Protection and Inheritance of Local Culture in the Construction of New Urbanization}

Get rid of the wrong idea and eliminate the prejudice of local culture.First of all, get rid of the wrong idea, correctly understand the local culture. Local culture is the foundation of the development of the city, and it is thought that the local culture is the idea and prejudice of the backward culture and the low end culture. Secondly, we should face up to the local cultural crisis and rebuild the local cultural emotion. The unbalanced development of urban and rural community, rural self development ability in the long run backward, more vulnerable to contempt, disadvantage and development, the pursuit of interests and the development of the countryside has become a common phenomenon. In this regard, we have to face up to this crisis, thinking about the causes of the crisis, to seek solutions to the local culture can be taken seriously and heritage. At the same time, in the construction of the new urbanization, to cultivate the public's recognition of the local culture, there can be recognized in the sense of responsibility and protection. Through education, publicity and other forms to improve the public and the whole society to pay attention to the local culture and heritage protection awareness.

To strengthen policy support, improve local cultural laws and regulations. On the protection of local culture, not only to improve people's awareness of protection, more importantly, to strengthen government policy support and the introduction of local cultural protection laws and regulations. Establish and improve the protection mechanism of local culture. Strengthen the relevant legislation, punish the destruction of local culture. At the same time, the establishment of a reasonable and effective special funds to ensure that the local cultural heritage and protection of the work can be carried out smoothly. It is also necessary to build up a contingent of talents who are protected by local culture, and train professional talents, so as to enable them to effectively manage and plan the relevant matters concerning the protection and inheritance of local culture.

To explore the mode of construction of ecological livable towns. Urbanization central work conference stressed: "in promoting the integration of urban and rural development, should pay attention to keep the original style of the village, carefully cut trees, not filling the lake, less demolition", "the development of historical memory, geographical characteristics, national characteristics of the beautiful town". The current urbanization focus on highlighting local characteristics, such as the establishment of ancient villages and towns tourism scenic area; development of rural ecological town; the establishment of local cultural museum; a folk museum and cultural life to establish a traditional experience base and so on. These models explore, will effectively promote the promotion of urbanization and cultural heritage, especially important is to promote the construction of ecological livable modern towns.

\section{Conclusion}

Although the status of folk culture is important, but the number is huge, scattered distribution, resulting in not being protected. Under the erosion of time, these legacies are on the decline, and many are almost at the edge of extinction. In addition to the traditional forms of protection, we take digital means to protect more scientific and effective. But the protection of folk cultural heritage 
should be a universal behavior, all the people should act, for our children and grandchildren to see these great art and fulfill their duties.

\section{References}

[1] Xin Zhiyang. The Important Value of Local Culture in the Improvement of Rural School Moral Education [J]. Journal of Anhwei Normal University, 2012 (6);

[2] Fan Ruili. The Origin and Evolution Path of Rural Informal Finance in China [J]. Jiangsu Agricultural Sciences, 2011 (4);

[3] Deng Hui. Analysis and Design of Personalized Learning System for Students' Characteristics [J]. Journal of Distance Education, 2006, (5);

[4] Cai Zhiguo. The Rural Cultural Narrative of the Rural Drama Since the Reform and Opening up [J]. Voice and Screen World, 2015(6);

[5] Cao Peijie. Research Status and Future Development of Digital Natives [J]. Educational Research, 2012, (4);

[6] Sun Ling. New Features of Liaoning Local Culture from the Perspective of New Farmers[J]. Journal of Shenyang University, 2014, (2) 